\title{
Por Que Ler Hobbes como um Teórico de Segurança Internacional?*
}

\author{
R. B. J. Walker**
}

Thomas Hobbes tornou-se uma figura canônica para teorias de segurança internacional, ainda que seus escritos digam relativamente pouco acerca do que chamaríamos hoje de um sistema internacional. Muitos especialistas concordam que ele deveria ser entendido acima de tudo como um teórico da política dentro dos Estados e, especialmente, como um teórico da autoridade soberana de Estados particulares. Contudo, atualmente, é quase impossível dissociá-lo de análises de Relações Internacionais em geral e de argumentos sobre rea-

\footnotetext{
** Artigo recebido e aprovado para publicação em maio de 2010. Traduzido por Victor Coutinho Lage.

** Ph.D. em Ciência Política pela Queen's University, professor de Ciência Política da University of Victoria, Canadá, e professor de Relações Internacionais do Instituto de Relações Internacionais da Pontifícia Universidade Católica do Rio de Janeiro (IRI/PUC-Rio). E-mail: r.b.j.walker@keele. ac.uk.
} 
lismo político e segurança em particular. Este artigo desenvolve três maneiras de se pensar sobre o status desconcertante de Hobbes a esse respeito. Sugere-se que Hobbes, ao fim e ao cabo, permanece importante para a análise de segurança internacional, assim como para a teoria política de modo mais geral, não por desenvolver qualquer teoria coerente de Relações Internacionais, mas sim porque sua consideração sobre a soberania de Estados particulares exige uma avaliação sobre as condições de possibilidade externas de tais Estados. Essas condições devem ser entendidas menos em termos de uma teoria de Relações Internacionais e mais como considerações constitutivas de uma espaço-temporalidade moderna que torna possível que teorias modernas de relações internacionais sejam fundamentadas em uma filosofia da história específica. É nesse contexto que podemos entender a relação poderosa, porém amplamente não reconhecida, entre teorias de Relações Internacionais e teorias de modernização, e, portanto, o que está em jogo na identificação equivocada de Hobbes como um arquétipo realista político.

\section{$* * * *$}

Hobbes (1991, p. 11) introduziu o livro Leviatã, argumentando que "Aquele que vai governar uma nação inteira deve ler, em si mesmo, não este ou aquele homem em particular, mas a humanidade". Além disso, sobre o método por ele adotado para tal leitura, argumenta que "esta doutrina não admite outra demonstração" (HOBBES, 1991, p. 11).

Nenhum dos dois argumentos é trivial. Um dirige-se à possibilidade de uma política envolvendo não apenas homens individualizados e fisiologicamente psicologizados particulares, como também uma nação e um entendimento específicos da humanidade em geral. Desse modo, talvez, quando lido retrospectivamente, refira-se ao que viemos denominar sistema internacional, entendido como expressão de uma humanidade comum, assim como ao Estado, entendido como 
Por Que Ler Hobbes como um Teórico de Segurança Internacional?

uma expressão de um grupo particular de cidadãos individualizados entre outros grupos de cidadãos. Este é um argumento que, entre outras coisas, engaja a dupla possibilidade, ou impossibilidade, de reconciliar "homens" e "cidadãos", a qual ainda molda muito do que sabemos (e das condições sob as quais fazemos julgamentos) sobre necessidades e possibilidades políticas modernas, tanto dentro dos Estados quanto entre Estados. O outro argumento refere-se a uma maneira particular de conformar relações entre possibilidade e necessidade; e, portanto, à construção de maneiras caracteristicamente modernas ou até mesmo liberais de se pensar sobre liberdade dentro e para além de vários tipos de condicionalidade, assim como a uma afirmação da relação positiva entre argumentos sobre método e a expressão de ambição política. Esses argumentos possuem uma rica e contestada linhagem histórica. Eles continuam a ter uma presença intimidadora na maneira pela qual nos engajamos com as possibilidades e os limites da vida política contemporânea. Eles conservam sua presença não menos importante em relação aos rituais, quer plausíveis ou implausíveis, por meio dos quais o nome de Hobbes se tornou implicado no pensamento sobre uma política que é de alguma maneira internacional.

Assim como grande parte do resto do texto de Hobbes, no entanto, esses argumentos dizem muito pouco diretamente sobre qualquer sistema interestatal ou internacional como hoje poderíamos entendê-lo. Há pouca dúvida de que a força primária da argumentação de Hobbes é dirigida internamente, isto é, à formação de sujeitos políticos individualizados modernos dentro de um Estado soberano concebido como um tipo de sujeito político mais amplo, coletivo e, portanto, distinto. Em face disso, de fato, o elo que se tem estabelecido com frequência entre Hobbes e várias teorias de Relações Internacionais parece bastante tênue, como acredito que seja em muitos aspectos. Hobbes ajusta-se muito mais facilmente às literaturas canônicas da ascensão do Estado soberano moderno do que a qualquer conside- 
ração canônica de uma teoria de Relações Internacionais, assumindo que quaisquer reivindicações como esta possam ser claramente identificadas. Contudo, assim como até mesmo com as conceitualizações mais solipsísticas de subjetividades modernas, Hobbes é forçado a sinalizar em direção a algumas condições externas da própria possibilidade da política de sujeitos soberanos modernos que ele traz à tona dentro de uma concentração particular de autoridade legalizada. Pode ser difícil de argumentar que os gestos de Hobbes nessa direção sejam especialmente sistemáticos ou persuasivos, ainda que se esteja preparado para aceitar a analogia popular, porém equivocada, entre indivíduos em um estado de natureza e Estados em um estado de guerra. Ainda, Hobbes de fato exige certa concepção de uma ordem externa de algum tipo até mesmo para iniciar seu argumento de uma ordem política interna; e a política do começo é uma parte assaz significativa, para não dizer decisiva, das preocupações de Hobbes.

Portanto, é encorajador que uma crescente atenção esteja sendo conferida a como poderíamos entender não somente o que Hobbes tinha em mente ao se referir a fenômenos que chamaríamos agora de internacionais em certo sentido (anacrônico), mas também ao que poderia estar envolvido ao se pensar sobre alguma política (internacional ou pós-internacional) que seria menos devedora de sua imponente presença. Ainda assim, parece-me ser menos útil perseguir aquelas relativamente poucas ocasiões em que Hobbes de fato fala algo de interesse teórico sobre o que poderíamos chamar de relações internacionais do que pensar acerca do modo como Hobbes estabelece um argumento geral das possibilidades e impossibilidades políticas modernas nas quais algum tipo de mundo externo desempenha claramente um papel crucial. Isso ocorre em parte porque Hobbes realmente não diz tanto assim sobre como uma ordem internacional poderia operar, o que pode ser explicado simplesmente porque, mesmo com sua extraordinária capacidade premonitória, foi assaz difícil decifrar como exatamente as decadentes hierarquias e as matizadas ju- 
Por Que Ler Hobbes como um Teórico de Segurança Internacional?

risdições da Europa na Baixa Idade Média poderiam eventualmente gerar as relações sistêmicas e as determinações estruturais de um sistema internacional moderno, concluído com os nacionalismos dos séculos XIX e XX, em vez de com os tipos de nações que Hobbes parece ter tido em mente. Kant foi certamente mais premonitório do que Hobbes a esse respeito e possui um argumento muito mais forte do que Hobbes como a figura que esboça as linhas gerais de uma ordem política que é simultânea e precariamente predicada em princípios de autoridade soberana distribuídos entre indivíduos, Estados e um sistema de Estados. Todavia, quero argumentar aqui, é útil pensar sobre a maneira como Hobbes já presumiu uma ordem externa de algum tipo, a fim de construir sua consideração da autoridade soberana dentro de um Estado particular.

Na minha visão, em suma, Hobbes de fato oferece um lugar muito útil para se pensar sobre as realizações e os transtornos de uma ordem política internacionalizada moderna; no entanto, isso ocorre menos em função de seus esporádicos comentários sobre um estado de guerra, por mais instrutivos que possam ser em alguns aspectos, e mais pela sua maneira de estabelecer a própria possibilidade de uma ordem política, interna e externa, na qual tanto a "humanidade" quanto aqueles que devem ser governados em "nações inteiras" poderiam entrar. Se faz sentido refletir sobre possibilidades políticas contemporâneas e suas condicionalidades pensando sobre uma teoria política internacional após Hobbes, eu diria que uma ajuda seria se tornar mais sensível a alguns dos problemas gerais aos quais Hobbes tentou responder e aos recursos conceituais com os quais tentou fazê-lo. Como de costume, é um grande erro tentar se engajar nesse material como se os momentos interno e externo da política moderna pudessem ser simplesmente divididos em dois e distribuídos em discursos disciplinares mutuamente exclusivos. Hobbes, quero sugerir, é interessante para engajamentos contemporâneos com uma política internacionalizada, em virtude dos movimentos conceituais que foi capaz 
de fazer sem muita referência a qualquer tipo de internacional como hoje entenderíamos, ainda que eles lhe tenham exigido a referência a um entendimento particular do que obrigatoriamente se situa para além de e dentro do seu universo imaginário de sujeitos modernos.

Os dois argumentos introdutórios de Hobbes podem ser lidos, de um modo filosófico, em relação a um entendimento específico de uma lógica geral de argumentação, a qual estava, à época, moldando uma alteração decisiva (embora, em termos históricos, ainda indeterminada) em direção ao que hoje chamamos de (uma forma particular de) modernidade. Eles também podem ser lidos, de um modo mais histórico, como um conselho normativo a alguém em particular, envolvido nos acasos cambiantes da Inglaterra revolucionária. De fato, grande quantidade da literatura recente mais impressionante sobre Hobbes vem sendo moldada por preocupações específicas de tradições filosóficas e históricas distintas, embora valha a pena enfatizar que tais tradições não se traduzem automaticamente, ou mesmo facilmente, em um entendimento político da significância de Hobbes como um pensador político, especialmente, mas não apenas, sob condições contemporâneas.

De qualquer um dos modos, no entanto, e não importa o que se extraia do rigor lógico de suas deduções ou da força retórica de suas narrativas, ou talvez especialmente da sua extraordinária habilidade de escrever de maneiras que se dirigem tanto a alterações épicas quanto a manobras locais voláteis, seus argumentos introdutórios não têm exatamente garantido acordo sobre qual foi com precisão sua doutrina ou mesmo quais eram suas premissas mais cruciais. Ao contrário, interpretações concorrentes do Leviatã proliferaram desde sua publicação. Elas continuam a animar muito da forma e da substância da teorização política contemporânea. Tentativas de contextualização histórica de sua obra têm sido especialmente populares 
Por Que Ler Hobbes como um Teórico de Segurança Internacional?

nas décadas recentes, mesmo até o ponto em que possuem o efeito um tanto paradoxal de entrincheirar seu status como uma figura canônica, como um exemplar primário de inovações políticas europeias do início da modernidade. De modo oposto, tentativas de operar por meio da lógica de sua argumentação rapidamente se dissipam por múltiplos campos de engajamento acadêmico em mundos intelectuais que permanecem bastante obscuros para nós. Assim como a suposta transição do período medieval para o moderno, na qual se supõe que ele tenha sido uma figura de enorme relevância, Hobbes pode ainda se destacar para nós tanto como um renitente clichê quanto como na condição de um lugar de mistérios ainda demandantes de um trabalho acadêmico muito mais pesado por parte igualmente de filósofos e historiadores.

Muitas pessoas notaram que renitentes clichês, e não apenas sobre Hobbes, têm sido uma característica penetrante nas teorias de Relações Internacionais anglo-americanas conforme construídas no curso do século XX. Muitos desses clichês, alguns envolvendo Hobbes, vêm sendo desafiados pelo trabalho de vários historiadores e filósofos que têm emergido gradualmente a partir do que tem sido com frequência uma empreitada um tanto hermética. Lidos nos termos acadêmicos que seriam análogos tanto aos filósofos quanto aos historiadores, desafios às considerações recebidas que situam Hobbes como a fonte arquetípica do realismo político, o qual se supõe ter sido a forma primária de teoria de Relações Internacionais, foram bastante diretos; tão óbvios como dois e dois são quatro. Mesmo assim, reclamações assaz elementares sobre os nomes clichês de cânones estabelecidos são facilmente desconsideradas por razões que precisam ser engajadas, algumas vezes com recursos que podem estar disponíveis a partir de uma sociologia política de instituições e disciplinas, algumas vezes a partir de considerações das práticas de legitimação de Estados modernos e algumas vezes a partir do que se quiser encontrar de ainda útil nos destroços de várias formas de crítica a ideologias. 


\section{R. B. J. Walker}

Em companhia de Kant, Hobbes há muito vem sendo forçado a emprestar seu nome a uma das duas possíveis posições que foi aconselhável que se adotasse em todas as questões de controvérsia ontológica e axiológica quando se pensa sobre uma ordem política internacionalizada, de maneiras que tenderam a confirmar uma ordem normativa específica de Estados soberanos agindo dentro de um sistema determinado desses Estados. Não há um único pensador que poderia ser forçado a arcar com essa responsabilidade por muito tempo; na mesma medida em que nenhuma categoria única de realismo político poderia abarcar a gama de posições ontológicas e axiológicas que foram empacotadas juntas como o polo privilegiado de uma disciplina bipolar. Mesmo um engajamento casual com a literatura secundária, para não dizer alguma leitura dos textos de Hobbes (ou, ao menos, qualquer coisa a mais do que o décimo primeiro e o décimo terceiro capítulos), poderia rapidamente prover bases para se suspeitar de que o suposto realismo de Hobbes não era exatamente o que parecia. $\mathrm{Na}$ maior parte das vezes, no entanto, leituras tanto do texto de Hobbes como da literatura secundária foram eventos raros. Clichês permaneceram e ainda permanecem penetrantes.

Isso não se deve a qualquer escassez de produção acadêmica oferecendo considerações mais sofisticadas do que Hobbes estava tentando fazer, ou ainda de com que recursos e com que efeitos o fazia. Além disso, alguns dos obstáculos mais óbvios ao engajamento com esse material (como os constrangimentos da Guerra da Fria, as demandas por uma orientação pragmática da política de Estado e a disposição contra a pesquisa teórica que vinha com formas influentes de ciência social) retrocederam levemente, mesmo que apenas levemente, e de modo um tanto desigual. Novas orientações para questões teóricas e a leitura de textos prosperaram, ainda que mais em alguns lugares do que em outros. Entretanto, clichês também prosperam. Talvez prosperem especialmente onde as disciplinas acadêmicas se deparam com o comércio de manuais. Porém, também prospe- 
Por Que Ler Hobbes como um Teórico de Segurança Internacional?

ram onde as formas mais sofisticadas de pesquisa são conduzidas e onde as questões mais difíceis são formuladas sobre o que significa falar sobre formas internacionalizadas de vida política, ou imaginar o que a vida política poderia envolver, se tais formas não pudessem ser sustentadas. Muitos recursos estiveram disponíveis por muito tempo para desafiar não apenas reivindicações sobre Hobbes como o realista político exemplar, mas também várias categorias e debates que alcançam muito de sua plausibilidade por intermédio de maneiras pelas quais Hobbes é evocado nessa linha.

Portanto, ao passo que eu certamente aceito que a produção acadêmica recente em Hobbes tem muito a dizer acerca de como seria possível construir considerações mais persuasivas historicamente, rigorosas conceitualmente e produtivas politicamente (e enfatizo a tensão plural a esse respeito) de Hobbes como uma figura que tenha algo a dizer sobre relações internacionais, passadas, presentes ou futuras, penso ser necessário ter atenção ao modo pelo qual Hobbes vem sendo lido, e em alguns aspectos tem que ser lido, dentro desse específico campo ou disciplina. A redescoberta de um Hobbes diferente, mais complexo ou menos unidimensional, é um exercício útil. Um maior reconhecimento de que Hobbes foi e continua a ser aberto a interpretações rigorosamente diferentes, com consequências profundas em jogo nos julgamentos acerca de interpretações rivais, seria ainda mais útil. Todavia, uma apreciação do que pode estar envolvido no pensamento sobre teoria política internacional, ou mesmo sobre política, após Hobbes também exige alguma atenção a como algumas inscrições específicas e clichês de Hobbes dentro de formas predominantes de teoria política internacional vieram a operar tão efetivamente.

A fim de me engajar com o que está em jogo em mover-se para longe dos comentários mais explícitos de Hobbes sobre uma ordem internacional, ou ao menos sobre um estado de guerra, em direção ao seu enquadramento geral de uma política de internalidades e subjetivida- 
des que, no entanto, exige algum tipo de externalidade como sua condição de possibilidade necessária, trabalharei brevemente com três modos de respostas a questões acerca dos motivos das teorias modernas de Relações Internacionais parecerem ter exigido uma figura como Hobbes para ancorar premissas sobre uma tradição dominante de realismo político que pode tanto ser confirmada quanto ser resistida. Procedo assim porque parece fazer pouco sentido continuar a reproduzir um conjunto de manobras conceituais por meio da afirmação ou da resistência a uma figura que foi estabelecida precisamente para encorajar a afirmação ou a resistência.

Uma resposta concerne aos argumentos relativos à sua ética, concebida muito amplamente. Outra diz respeito à sua descrição de uma condição de anarquia e à crucial tensão entre considerações individualistas, estadistas e sistêmicas dessa condição. A terceira refere-se ao seu enquadramento de uma ordem espaço-temporal dentro da qual as relações entre sujeitos modernos poderiam ser imaginadas. Esta última, já prefigurada em seus dois argumentos introdutórios, é, creio, de longe a mais importante e oferece algumas possibilidades para tornar Hobbes, ao invés de um clichê canônico, um lugar provocativo de questões que permanecem difíceis. A coisa mais urgente em jogo nessa última resposta é a maneira pela qual a teoria política internacional parece se preocupar com um leque de possibilidades políticas orquestradas espacialmente, ao passo que sua primeira realização tem sido autorizar essa consideração espacializada específica de possibilidades, e necessidades, políticas por meio de uma reivindicação sobre uma filosofia da história. Essa filosofia da história pode ser entendida como a temporalidade que tão frequentemente é reprimida ao se pensar sobre formas modernas de soberania modeladas em algo como as inovações de Hobbes, porém que com tanta frequência retornam como uma exceção no momento espaço-temporal da decisão soberana.

Se for para haver uma política após Hobbes, ela precisará, em primeiro lugar, tratar dos efeitos constitutivos dessa filosofia da história par- 
Por Que Ler Hobbes como um Teórico de Segurança Internacional?

ticular, que Hobbes em ampla medida compartilha com aquele que se supõe ser seu oposto, Immanuel Kant. Em segundo lugar, no entanto, sugerirei que também é importante lidar com as implicações da relativa ausência do que chamaríamos de um sistema internacional a partir da análise de Hobbes. A mera existência de outros soberanos não resulta em um sistema de Estados. Somos influenciados de maneira excessiva por considerações radicalmente nacionalistas ou, ao menos, radicalmente estadistas do internacional como sendo meramente o produto da soma dos interesses estatais. Isso pode ser conveniente para aqueles Estados que geraram em larga medida as considerações mais privilegiadas das relações internacionais a partir de uma perspectiva estadista, e pode em parte explicar como um teórico do Estado soberano como Hobbes tem sido transformado tão facilmente em um teórico de política internacional. Não é especialmente interessante, contudo, para qualquer um em busca de pensar para além de uma ordem política na qual a soberania é sempre bruscamente contestada entre, ao menos, o Estado, o sistema de Estados e aqueles indivíduos quasi-hobbesianos que conseguiram articular reivindicações sobre uma soberania popular. Nesse sentido, meus comentários são dirigidos em parte à possibilidade de se usar Hobbes para adquirir algum ganho crítico a respeito da figura de Kant, cujo nome indiscutivelmente gera dificuldades ainda maiores do que as identificadas com Hobbes, em grande medida por possuir um sentido muito mais nítido do que significa se engajar com um sistema de Estados de modo tão sério quanto em qualquer Estado particular.

$* * * *$

O uso mais corrente de Hobbes na construção de uma teoria moderna de Relações Internacionais pode ser simplesmente sua visão assaz pessimista de uma condição humana. Esta é uma construção que poderia basear-se em uma variedade de formulações distintas: no seu psicologismo egoísta; na sua consideração exemplar de uma dinâmica generalizada de desejo abarcando uma pluralidade de desejos di- 
ferentes que, no entanto, cessam somente na morte; ou em sua consideração das contradições estruturais que ocorrem dentro de um arranjo de tais máquinas desejantes modernas sob condições de competição desregulamentada. Adicione sabores algo amargos a partir do Velho Testamento e de outras poucas fontes, e não fica tão difícil reduzir tudo a um útil pessimismo genérico. Isso pode ser então usado, por sua vez, como um ingrediente primário no cozido enegrecido que é celebrado tão persistentemente como realismo político e que se tornou a principal fonte evidente de sustância intelectual para tantas formas de teoria política internacional, incluindo formas que buscam explicitamente resistir à influência de Hobbes.

Hobbes é um pensador sutil, certamente muito mais sutil do que a maior parte das referências a um realismo político em teoria política internacional que evoca seu nome. Na melhor das hipóteses, o realismo político é uma reivindicação que poderia ser especificada em termos de algumas tradições muito diferentes e a rigor poderosas de pensamento político, ainda que seja obscuro se qualquer dessas tradições puder ser utilmente enquadrada como um realismo político. Hobbes pode ou não ser entendido em relação a uma dessas tradições; no entanto, o mesmo vale para Maquiavel, para citar o parceiro mais obviamente perturbador de Hobbes em qualquer tradição supostamente singular. A partir de certo ponto de vista ético universalizante, é possível que todos os céticos e pessimistas tendam a se assemelhar. Contudo, a partir de um ponto de vista de diferente tipo - histórico, filosófico e político -, Hobbes e Maquiavel são mais conhecidos como exemplares de posições contrastantes: na condição de um republicano e de um tipo de liberal, por exemplo, ou de um pensador obcecado com questões acerca de julgamentos contingentes no tempo e um pensador obcecado com a autorização de uma autoridade duradoura dentro de uma ordem espacializada. De um modo similar, as tradições de política de poder histórica e nacionalmente orientadas que se estendem de (ao menos) Max Weber a (de novo, ao menos) Hans Morgenthau são regularmente confundidas com as análises es- 
Por Que Ler Hobbes como um Teórico de

Segurança Internacional?

truturais, sistêmicas e utilitárias de ordens espacializadas, associadas em anos recentes a pensadores como Kenneth Waltz.

O grande talento de reivindicações sobre o realismo em teoria política internacional, de fato, reside em uma capacidade de contrair posições dramaticamente diferentes em um monólito discursivo, embora seja um monólito que reserva uma capacidade impressionante de cobrir grande número de opções ontológicas, epistemológicas e axiológicas. Demanda apenas um pouco de reflexão para apreciar que o cozido negro e amargo do realismo político continha muitos ingredientes que não funcionavam verdadeiramente bem juntos, a não ser que houvesse uma fome urgente e um tanto não acadêmica por algo tão não palatável, como houve em alguns contextos. De fato, o que pode merecer considerável desprezo de bases acadêmicas merece, ao mesmo tempo, alguma apreciação com base na resiliência retórica e discursiva.

Para simplificar um pouco, porém apenas um pouco, o que é de interesse urgente para teorias de Relações Internacionais é menos qualquer preocupação específica com as consequências do egoísmo individual e do conflito entre indivíduos do que a possibilidade de transposição de uma visão amplamente negativa da "natureza humana" para um contexto internacional no qual uma visão pessimista da condição humana é largamente entendida por contraste com as condições mais otimistas que se supõe que estejam em voga domesticamente, e não menos como uma consequência da ordem social moldada por algo como uma consideração hobbesiana de autoridade soberana dentro dos Estados. Nesse contexto, leituras detalhadas de escritos de Hobbes não vêm ao caso. Hobbes tem sido muito mais atraente como um pensador protoiluminista que pode ser usado para afirmar visões mais caracteristicamente contrailuministas: talvez como uma fonte mais fundacional (e anglo) de pessimismo que pode ser provida por historicistas e nacionalistas como Weber. O problema estruturante da política moderna com base em uma distinção (mas não separa- 
ção) entre políticas doméstica e internacional adquiriu uma distinção similar entre duas formas diferentes de possibilidade e impossibilidade política: nos influentes termos de Martin Wight (1966), entre uma arena doméstica na qual o progresso é possível e uma arena internacional que pode esperar apenas por repetição ou pelo mesmo e velho jogo de contingência e conflito; em termos um tanto mais dramáticos, entre um domínio doméstico dentro do qual normas podem ser tomadas mais ou menos como dadas e um domínio externo no qual condições excepcionais tendem a prevalecer. ${ }^{1}$

Eu diria que, na prática, a análise de Weber de um processo de modernização que opera simultaneamente como um processo de desencantamento, isto é, um processo formal de racionalização que é simultaneamente um processo demandante de escolhas existenciais sobre valor substantivo, tem sido mais influente do que Hobbes na construção de teorias modernas de relações internacionais. Hobbes pode ter oferecido uma via interessante para se pensar em sujeitos modernos como similares, porém diferentes, como unificados em sua "natureza" de máquinas desejantes, porém distintos na expressão de sua natureza universal. A consideração de Weber da modernização como um processo universalizante demandante de compromissos e responsabilidades diante de Estados-nação particulares oferece uma formulação completamente mais urgente, embora os psicologismos mais anistóricos de Hobbes ofereçam uma útil corroboração, em especial em virtude da necessidade de minimizar conexões entre uma ciência social estadunidense recém-estabelecida e as tradições dúbias do nacionalismo alemão. Em todo caso, formulações hobbesianas podem ser amplamente penetrantes, no entanto são dificilmente decisivas. Visões pessimistas do que se considera natureza humana não são exatamente raras. A necessidade capital não é operar a partir de primeiras premissas sobre natureza humana, quer entendida psicológica ou estruturalmente, mas orquestrar a divisão entre os domínios interno e externo da política moderna: a divisão que pode se tornar 
Por Que Ler Hobbes como um Teórico de Segurança Internacional?

uma completa ruptura somente sob as condições mais excepcionais; ou seja, condições que apenas confirmam a normalidade de orquestrações menos dramáticas da divisão. Hobbes aqui provou ser um símbolo muito útil, porém principalmente porque foi possível transcrever uma consideração supergeneralizada de seu pessimismo do domínio doméstico, que o preocupa na maior parte do tempo, para o domínio internacional, que o preocupa somente de maneira marginal.

$* * * *$

Essa transcrição também é central para um segundo uso capital de Hobbes em teoria política internacional, o uso da analogia desenhada entre indivíduos e Estados em argumentos sobre uma anarquia internacional. Este é o contexto no qual os capítulos 11 e 13 algumas vezes encontram de fato leitores nesse campo. Há dois problemas relacionados e óbvios com essa analogia. Ambos têm sido notados por grande parte de acadêmicos que procuraram os comentários de Hobbes sobre fenômenos extradomésticos.

Um problema é que uma parte muito ampla do argumento primário de Hobbes se preocupa em insistir que indivíduos e Estados soberanos são coisas muito diferentes. Indivíduos firmam um contrato com outros indivíduos para criarem algo que não pode ser reduzido a indivíduos. Isto é, em parte, uma questão de diferença no status legal, que gera muitos problemas característicos sobre a relação entre soberania estatal e soberania popular, para usar uma linguagem mais tardia. É também, em parte, uma questão de escala, a qual gera muitos problemas característicos sobre as maneiras pelas quais o micro poderia ser representado no macro, para usar uma linguagem que atinge algumas das inclinações mais euclidianas de Hobbes. É, ainda, parcialmente, uma questão de capacidades, na medida em que Estados não são tão vulneráveis à mortalidade como os indivíduos, podendo até mesmo ser bem-sucedidos em guerra. As armas podem apontar para 


\section{R. B. J. Walker}

fora, porém a vida dos Estados não é necessariamente sórdida, pobre, embrutecida ou curta, embora possa não ser bonita (HOBBES, 1991, capítulo 13).

Por conseguinte, se a analogia é de fato para ser considerada útil, deve sê-lo obrigatoriamente de maneiras que estejam seriamente em desacordo com a própria análise de Hobbes. Enquanto a analogia pode ou não ser útil na construção de estratégias explicativas, em companhia de analogias derivadas de muitas outras práticas estruturalmente orientadas, ela opera para dissolver alguns dos problemas mais difíceis da vida política moderna; mais especificamente, para converter a problemática e continuamente contestada relação entre soberania estatal e soberania popular em considerações homogeneizadas do Estado-nação e de algum interesse nacional. É difícil que seja surpreendente que formas de realismo político (ou, a rigor, reivindicações sobre o político) construídas dessa maneira tendam a excluir bastante da política.

Por outro lado, a analogia pode ser feita para ressoar muito bem em algumas outras considerações de ação racional que começaram a se articular não muito tempo depois de Hobbes por pessoas que tendemos hoje a classificar como os economistas políticos iniciais e por várias outras tradições por meio das quais a perseguição de autointeresse estava sendo entendida como uma fonte de algum bem comum, em vez de uma anarquia egoística. ${ }^{2}$ Muito do ímpeto por trás do que veio a ser chamado realismo estrutural ou neorrealismo pode ser entendido mais produtivamente em relação não tanto a uma tradição política que privilegia entendimentos hobbesianos de soberania estatal, e sim a amplos antagonismos de princípios históricos entre a autoridade dos Estados e a autoridade de mercados capitalistas. O próprio Hobbes, por óbvio, foi famosamente cauteloso com metáforas e um pouco mais generoso com analogias. No entanto, qualquer tentativa de se pensar sobre teoria política internacional com e contra Hobbes, como eu enquadraria muito da tarefa diante de nós, exigirá 
Por Que Ler Hobbes como um Teórico de

Segurança Internacional?

considerável cautela acerca do modo pelo qual uma analogia que o próprio Hobbes não poderia desenhar ainda permite que questões demasiado importantes sobre os princípios que guiam formas modernas de vida política passem em relativo silêncio.

O interesse específico de Hobbes a esse respeito é menos em sua versão da lógica de conflito sob condições de competição do que em seu arrojado reconhecimento de que, caso se inicie a partir de uma consideração de indivíduos modernos como livres e iguais, em entendimentos muito específicos desses termos, é possível construir uma história muito negativa sobre as consequências de compromissos com o que geralmente é tido como dois dos valores mais fundacionais de sociedades (liberais) modernas. Ainda, e para chegar ao segundo problema, a condição de igualdade é especificamente negada por Hobbes em relação a Estados. O compromisso de Hobbes com uma condição de igualdade entre indivíduos é bastante notável, dadas as práticas predominantes de subordinação hierárquica e essencialismo aristotélico (ou realismo filosófico) e não obstante as várias formas de desigualdade que ocorrem no admirável mundo novo de sujeitos modernos de Hobbes. Reivindicações predominantes sobre uma hierarquia natural são habilmente varridas, e a instabilidade estrutural de um universo de sujeitos modernos é revelada em toda a sua aparentemente primordial depravação. Todavia, é precisamente a ausência dessa condição que governa sua sensação de que o estado de guerra não é exatamente o mesmo que o estado de natureza que ele descreve entre indivíduos, não importando o quão negativamente ele às vezes retrata um estado de guerra. Tanto indivíduos quanto Estados podem estar inclinados para o cálculo racional, entretanto seu cálculo tende a ter um caráter muito diferente, e não somente em virtude da diferença constitutiva entre sujeitos individuais e coletivos.

Aqui pode ser útil pensar sobre a diferença entre um compromisso com igualdade formal na Assembleia Geral das Nações Unidas e o compromisso com desigualdade formalmente expresso pelas capaci- 
dades do Conselho de Segurança e informalmente pelas práticas de hegemonia de grandes potências. Reivindicações retóricas sobre uma anarquia internacional repousam em uma tácita analogia com a leitura de Hobbes de indivíduos modernos. Todavia, não pode haver muitos acadêmicos e práticos que pensam que essas reivindicações oferecem um modo útil de entendimento quer das estruturas, quer das práticas da política internacional moderna. Ninguém reivindicando uma capa de realismo político afirmará que os princípios que moldam a autoridade da Assembleia Geral irão prevalecer em algum momento sobre os princípios que moldam a autoridade do Conselho de Segurança, embora se possa argumentar que deveriam ou que nenhum dos dois conjuntos de princípios pode ou deveria ser sustentado sob condições contemporâneas. Conflitos e guerras podem ocorrer, porém há uma diferença um tanto significativa entre uma condição em que apenas poucos Estados possuam a capacidade de empregar armas nucleares e uma condição em que todos os Estados possuam uma capacidade mais ou menos igual para fazer isso.

Este é o motivo de Hobbes ser muito mais facilmente lido, na maneira de Hedley Bull (1977), como um precursor do que veio a ser conhecido como uma tradição de "sociedade de Estados" na análise política internacional do que como um teórico de uma anarquia política internacional, ou mesmo como um teórico de cálculo racional em algum tipo de nível de igualdade de interesses competitivos. Hobbes deixa abertas muitas questões a esse respeito. Uma delas concerne à possibilidade de qualquer grande potência se tornar grande o suficiente para tombar o sistema de Estados nascente de volta a uma ordem hierárquica ou imperium; a possibilidade contra a qual tanto as inovações conceituais de Hobbes quanto as reivindicações de uma ordem internacional foram delineadas mais agudamente. Outra preocupação são as restrições impostas a qualquer soberano específico pelas relações sistemáticas entre soberanos: uma razão pela qual Hobbes não pode absolutamente ser tratado como um sério teórico de Rela- 
Por Que Ler Hobbes como um Teórico de Segurança Internacional?

ções Internacionais e por que qualquer tentativa de se pensar sobre teoria política internacional após Hobbes tem que se engajar como muito mais do que Hobbes.

$* * * *$

Enquanto Hobbes diz pouco sobre as relações internacionais propriamente ditas, ele de fato diz muito sobre as condições específicas sob as quais formas modernas de política, incluindo o que chamaríamos hoje de relações internacionais, puderam em qualquer medida ser imaginadas. Movemo-nos aqui de maneira um tanto cautelosa para um terreno interpretativo ocupado mais por escritores inclinados a grandes narrativas sobre o caráter geral (embora não necessariamente atemporal) do pensamento político moderno (como Carl Schmitt, Leo Strauss, Michael Oakeshott e Sheldon Wolin) do que por historiadores atualmente mais influentes cuja procura por contextualização detalhada os faz acertadamente mais desconfiados de quaisquer grandes narrativas sobre a constituição de tradições políticas. Ainda assim, a teoria de Relações Internacionais é ela mesma uma das maiores narrativas que temos sobre o que a emergência histórica da política moderna deve obrigatoriamente ter sido, e histórias detalhadas não são necessariamente o modo mais adequado de se chegar ao que pode estar envolvido ao se pensar acerca das relações de Hobbes com isso.

Muitos temas poderiam ser enfatizados aqui. Observarei simplesmente cinco dos mais óbvios, a fim de apontar para o escopo do que tem que ser engajado. Nenhum deles é explicitamente sobre política internacional; a rigor, este é meu ponto. Todos se referem a uma concepção moderna de política que é sempre potencialmente internacional, assim como doméstica. Ao passo que, como sugeri, há problemas em usar ideias como as de Hobbes, que está primordialmente preocupado com as relações entre Estados e sujeitos internamente, para se pensar sobre as relações entre Estados. É também um equívo- 
co pensar que a relevância de Hobbes para o pensamento das relações entre Estados vem apenas daquelas partes de sua análise que falam especificamente sobre relações externas. Hobbes está trabalhando com sujeitos modernos, entendidos como um lugar do grande movimento moderno para dentro, em direção a um mundo de subjetividades cartesianas, protestantes, kantianas e muitas outras, assim como em direção ao mundo de sujeitos soberanos. Essas internalidades sempre presumem uma externalidade. A consideração de Hobbes da externalidade dos Estados pode não ser muito bem desenvolvida, porém grande parte de sua configuração básica está claramente no lugar, e no tempo.

Primeiramente, há a maneira pela qual Hobbes simplesmente afirma ao menos um contorno reconhecível de sujeitos modernos (liberais), a fim de tornar capaz "Aquele que vai governar uma nação inteira" de "ler, em si mesmo, não este ou aquele homem em particular, mas a humanidade". Ainda que a teoria de Relações Internacionais tenha sido organizada de maneira a minimizar a aparente relevância de questões sobre subjetividade e subjetividades, em prol dos grandes assuntos de Estados e de sistema internacional, Hobbes, como Kant ou Weber, e como algumas correntes mais recentes de análise crítica, não teria problema algum em ver de fato a subjetividade na condição de objeto primário de preocupação. Se tal subjetividade deve ser entendida como, digamos, liberal, democrática, individual, coletiva, de gênero ou marcada culturalmente é, sem dúvida, uma questão mais complicada. Hobbes pode ter sido bastante presciente sobre o que estava em jogo ao se estabelecer uma análise das relações entre pessoas livres e iguais, mais até, de certa forma, do que alguns dos seus sucessores supostamente mais liberais. No entanto, uma enorme quantidade de trabalho teve que ser feita para incitar suas abstrações mais básicas. Pode-se dizer também que muito resta a ser feito, com vistas a se estar confiante de que mesmo os princípios mínimos de liberdade e igualdade podem ser sustentados sob condições contemporâneas. 
Por Que Ler Hobbes como um Teórico de Segurança Internacional?

Tornou-se suficientemente fácil dizer que precisamos dispensar Hobbes; no entanto, não é de forma alguma fácil pensar como podemos sustentar argumentos plausíveis sobre sujeitos e subjetividades modernos sem tratar de muitos dos problemas com que Hobbes foi forçado a se engajar no intuito de afirmar sua particular interpretação da possibilidade e impossibilidade humana como o centro de atenção.

Em segundo lugar, há o nominalismo de Hobbes, o qual não o marca nem como um antiquado realista filosófico nem como um realista filosófico moderno ingênuo. Os detalhes são complicados, obviamente. Ainda assim, mesmo o conhecimento mais breve da maneira pela qual Hobbes é afiado acerca de problemas de linguagem, de definição e da autorização do que se considera como autoridade em relação a ciência, religião e direito é suficiente para perturbar muitos do clichês padronizados encontrados em algumas teorias de Relações Internacionais. Hobbes confrontou alguns conflitos bastante dramáticos acerca de interpretações concorrentes do mundo, e sua solução envolveu a instanciação de uma autoridade legal abstrata, e não um poder totalizante de um Estado. Nesse aspecto, Hobbes estava envolvido com problemas de autoridade, direito e mesmo "discurso" em que se engajam convencionalmente pensadores que têm sido colocados nas caixas trivializadas reservadas para idealistas e teóricos críticos. Mais uma vez, ler Hobbes não por meio das caricaturas, e sim como uma das mais brilhantes considerações do que significa autorizar a autoridade - reivindicar soberania acerca do que significa reivindicar soberania -, é ver que as questões envolvidas ao se pensar sobre qualquer tipo de política que possa de alguma forma deixar Hobbes para trás se tornam um pouco mais claras e muito mais intimidadoras.

Em terceiro lugar, há o secularismo que nunca é tão secular: a questão de se Hobbes pode ou não ser parte do processo por meio do qual o aparente secularismo da política moderna ainda expressa velhos con- 


\section{R. B. J. Walker}

ceitos teológicos em um novo estilo, especialmente tendo em vista muitos debates contemporâneos sobre várias formas de soberania que ainda legitimam o tirar e o conceder a vida de maneiras que legitimam sua própria soberania. A recente popularidade de Carl Schmitt foi certamente útil ao iluminar em que grau as leituras concorrentes da tese de secularização e as ambivalências expressas em conceitos de Hobbes, qualquer que seja sua própria relação com questões teológicas, permanecem centrais para qualquer tentativa de se pensar sobre teoria política internacional em modos mais criativos.

Em quarto lugar, talvez um pouco menos óbvio, há o compromisso resoluto de Hobbes com uma política de finitude, o qual, no entanto, opera por intermédio de uma distinção arbitrária entre o mundo finito dentro do qual verdades universais são possíveis e algum mundo além no qual tais verdades são inimagináveis. Esta pode ser a coisa mais importante que Hobbes aprendeu de Euclides; defina a linha em relação aos dois pontos de cada limite, assim suprimindo a necessidade de pensar sobre a maneira pela qual essas linhas continuariam indefinidamente, e, com isso, um universo de verdades necessárias de verdades garantidas por definições autorizadas - torna-se possível. A geometria usualmente identificada em termos de mero método possui precondições ontológicas profundas, e tais precondições encontram expressão significativa na consideração de Hobbes acerca da autorização de reivindicações universais de autoridade e de sua delimitação. Hobbes (1991, capítulo 3) simplesmente inclui infinitude entre um arranjo de entidades absurdas e encantadas cuja rejeição Weber usaria mais tarde como uma forma de caracterizar a qualidade essencial do processo de racionalização da modernidade. A distinção entre finito e infinito pode ter sido tão central para a construção, reprodução e delimitação de formas modernas de racionalidade quanto foram as distinções teológicas entre imanência e transcendência Kant é apenas a figura mais óbvia que vem em mente a esse respeito. Tentativas de "ir além" das convenções estabelecidas das Relações 
Por Que Ler Hobbes como um Teórico de Segurança Internacional?

Internacionais, e das formas modernas de política em geral, evidenciam parte da contínua capacidade de essas duas distinções construírem desejos pelo impossível, enquanto afirmam as necessidades tanto das possibilidades quanto das impossibilidades dentro do mundo finito e imanente de sujeitos e subjetividades modernas, grandes e pequenos. Uma vez mais, pense sobre a delineação de internalidades e externalidades nesses termos, e a contínua força de Hobbes na imaginação política moderna opera em um registro muito diferente dos seus comentários específicos sobre um estado de guerra.

Por fim, Hobbes é o teórico da soberania que de maneira mais clara insiste que ela sempre exige autorização. Grande parte do árduo trabalho feito no Leviatã já está completa muito antes de chegarmos a qualquer coisa que lembre um dilema de segurança no capítulo 11. A coisa principal que teóricos de Relações Internacionais devem recuperar antes de qualquer interrogação crítica das categorias ossificadas da disciplina erigidas durante a Guerra Fria ter se tornado possível não é algum corpo de ideais normativos a ser atirado na cara de autoproclamados realistas políticos, e sim alguma coisa como o senso de Hobbes do que está envolvido na autorização da autoridade soberana. Inspiração tática pode ter advindo de uma gama de pensadores "pós-modernos" com Jacques Derrida, porém isso ocorre em grande medida porque tais pensadores têm se engajado precisamente nas práticas fundadoras de tantas reivindicações de autoridade tradicional, embora seja usual, e irritante, que o tenham feito em relação a textos aparentemente filosóficos, ao invés de explicitamente políticos. Portanto, Hobbes pode ser tratado simplesmente como alguém que concedeu a definição padrão da autoridade soberana que moldou uma forma de ordem política na qual é muito fácil que se sinta sem saída e sem ajuda, como a fonte de respostas que temos que tomar como dadas. Ele pode ser lido também como nosso mais brilhante analista, e, portanto, potencial crítico, das condições sob as quais tais 


\section{R. B. J. Walker}

respostas, a armadilha, a impossibilidade de qualquer outra conclusão, vieram a se estabelecer.

A expressão mais explícita, bem conhecida, no entanto insuficientemente apreciada, do que Hobbes alcança nesse contexto mais amplo é a narrativa central de fundação que Hobbes conta após construir sua consideração das condições sob as quais se pode pensar sobre uma narrativa de fundação: o que conhecemos como sua teoria do contrato social. Isto é tão conhecido, e naturalizado, que é tomado tão somente como uma versão simplificada da história por meio da qual nós, ou ao menos alguns de nós, nos tornamos modernos. Era uma vez: vivíamos em um estado de natureza e então nos tornamos cultivados, cultos, civis, propriamente humanos, embora tenhamos nos acostumado a pensar sobre a mudança como um processo temporal (kantiano, hegeliano, darwiniano, desenvolvimentista, modernizador), em vez de pensá-la como um momento lógico. Contudo, o traço mais notável da representação de Hobbes desse estado de natureza é precisamente o fato de ser uma consideração formal não de algum passado histórico, mas de uma leitura negativa da consideração de Hobbes de sujeitos modernos, protoliberais livres e iguais. A visão de história de Hobbes é uma história do presente, ou ao menos da imaginação de Hobbes de como o presente deve obrigatoriamente ser entendido.

Nesse sentido, Hobbes estava auxiliando a moldar um entendimento caracteristicamente moderno do que a história deve obrigatoriamente ser, primordialmente pela articulação de uma consideração conjectural do que deve obrigatoriamente ter acontecido, para que sujeitos modernos tenham se tornado o que eles pensam que são. A rigor, o passado é projeto para trás a partir do presente. A esse passado é dada também uma dimensão espacial, na América, o espaço lá longe onde se pode achar evidências de um tempo lá atrás. As linhas geométricas 
Por Que Ler Hobbes como um Teórico de Segurança Internacional?

de extensão espaço-temporal partem da própria subjetividade constitutiva de Hobbes, mapeando as coordenadas pelas quais o homem moderno pode navegar para onde e quando ele já esteve, porém dessa vez em uma condição diferente, positiva, civil, e não natural. Mercator, o arquetípico cartógrafo do mundo moderno, pode ter sido bom, no entanto não foi tão bom.

Além disso, Hobbes parece ter entendido bastante bem que tais linhas de extensão espaço-temporal, de perspectiva histórica e geográfica projetada a partir dos olhos de Hobbes, o grande retratista dos sujeitos políticos modernos, podem ir ao infinito, aquele grande desconhecido capaz de destruir todas as tentativas de operar uma razão secular, porém universal. Hobbes sabia que não poderia ir lá, portanto parou exatamente nesse lado do inalcançável e incognoscível, exatamente onde ele poderia dizer que isso nunca foi de fato assim, mas também onde ainda restava a possibilidade de se mover sempre mais perto daquela infinitude que jamais poderia ser atingida. Isso não o salvou, todavia, da objeção óbvia que tem que aparecer diante de sua consideração acerca da maneira pela qual os homens retornam ao longo das linhas de projeção, por intermédio de um momento de decisão instantâneo de concordar com a desistência de uma condição, com vistas a adotar outra: se a situação fosse tão ruim como lá se anunciou, não haveria como mudar condições, a não ser pela introdução de capacidades excepcionais que poderiam momentaneamente tornar o negativo positivo, ao passo que, se a situação fosse benigna o suficiente para permitir tais acordos, então a análise racional para a mudança de condições simplesmente perderia sua plausibilidade.

Isto é uma história meramente hipotética, e uma geografia hipotética. Ainda assim, o que Hobbes está fazendo aqui é nada menos do que estabelecer um campo espaço-temporal dentro do qual é possível imaginar uma ordem internacional de algum tipo. Essa própria ordem foi imaginada como finita, porém esta finitude foi construída com sua própria externalidade, o mundo desconhecido e sempre po- 
tencialmente infinito além daquele que pode ser conhecido. Hobbes estava participando, por meio disso, da construção de considerações especificamente modernas tanto de espacialidade quanto de temporalidade; e esta pode ter sido a coisa mais importante que Hobbes faz para a maneira pela qual entendemos dimensões especificamente internacionais da ordem política moderna. Há ainda pouco sentido de um sistema, do sistema que pode ser universal em algum sentido, porém ainda não alcança e toca o mundo. Há ainda menos um sentido de um sistema com uma reivindicação de autoridade que seja necessariamente antagonista, e mesmo aporética, em relação às reivindicações de qualquer Estado soberano particular. No entanto, Hobbes provê o enquadramento amplo de uma interioridade dentro da qual tem sido possível construir um arranjo sistemático de internalidades e externalidades, o que denominaríamos a ordem política internacional moderna. É uma ordem moderna, de sujeitos modernos e subjetividades modernas. Venha para dentro e tudo ficará bem, contanto que de fato, o dilema de segurança - a solução não se torne pior do que o problema que ela resolve.

Hobbes pensou apenas em entrar no Estado. Somos forçados a pensar sobre entrar tanto no Estado quanto no sistema de Estados. Como resultado, somos forçados a pensar sobre as consequências de uma ordem política que distingue nitidamente as zonas de paz das zonas de guerra, uma ordem política na qual a possibilidade de guerra supostamente oferece alguma esperança para a manutenção das zonas de paz. Isso gera desejos de fazer tudo isso de uma outra forma. É dito que temos que agir em relação ao mundo inteiro; e é precisamente isso. Exceto pelo fato de que Hobbes, na companhia de muitos outros, já distinguiu o mundo de possibilidades políticas modernas de todos os outros mundos, temporais e espaciais. É nessa base que ele elabora uma história sobre as condicionalidades de sujeitos políticos modernos. O próprio Hobbes é um pouco vago e impreciso sobre tudo isso. Seu conjunto de figuras mentais é aquele da história espe- 
Por Que Ler Hobbes como um Teórico de Segurança Internacional?

culativa. Kant, mais uma vez, executa um trabalho muito mais incisivo, no que tange ao que significa operar uma política de finitude e os dilemas de representação e escala que acompanham um mundo moderno atado entre universalidade e particularidade, porém impossibilitado de ir além do seu entendimento específico de universalidade e particularidade, em direção a alguma infinitude incognoscível. Hobbes e Kant devem realmente ser tratados juntos nesse aspecto e, sem dúvida, não como estúpidos representantes de um realismo político e de um idealismo político.

$* * * * *$

Muitas severas questões ficam nítidas se pensamos Hobbes em relação às condições sob as quais temos sido capazes de imaginar uma ordem política internacionalizada que tem sido construída associada a uma ambição por sujeitos livres e iguais modernos que têm sido trazidos para dentro do mundo moderno e, assim, excluídos de qualquer outro mundo. ${ }^{3}$ Pensar em uma teoria política internacional após Hobbes tem que envolver um engajamento mais intenso com as condições sob as quais o próprio Hobbes foi capaz de imaginar seu elegante universo moderno de sujeitos e subjetividades livres e iguais: com a narrativa de um presente incluído que tornou possível uma narrativa de uma dupla exclusão do presente, uma interna e uma externa; com a narrativa de um retorno impossível, porém necessário, gerado por essa dupla narrativa; e depois, mas somente depois, com as narrativas de como a soberania tem que operar, dada a maneira pela qual tem sido autorizada a operar. Focar-se apenas na consideração explícita de Hobbes de um estado de guerra é perder quase tudo que faz de Hobbes um desafio de tal magnitude à vida política contemporânea, assim como focar-se na soberania como um lugar centralizado de autoridade é perder tudo de importante sobre como Hobbes projeta uma história acerca da origem necessária das coisas e, portanto, dos limites necessários das coisas, entre os quais pode, porém apenas pode, ser possível construir um centro de autoridade soberana. 
Talvez o centro não possa se manter; no entanto, é mais relevante pensar se os limites espaço-temporais que Hobbes delineou de maneiras que nos encorajaram a procurar a política apenas onde os centros podem se manter são ainda sustentáveis. Penso ser sem dúvida muito insensato aceitar as premissas a esse respeito. Sem tais premissas, contudo, pensar sobre as possibilidades de uma teoria política, internacional ou diversa, torna-se consideravelmente mais difícil do que se queixar da condição das teorias de Relações Internacionais ou do que pensar que se pode aprimorá-las simplesmente ignorando as realizações de Hobbes; ou melhor, as realizações das quais Hobbes é meramente uma expressão textualmente incisiva. Por outro lado, refletir sobre a condição das teorias de Relações Internacionais de fato nos ajuda a entender que uma teoria política que não se engaja com as condicionalidades internacionais da política moderna também deve ter pouco a oferecer. Ao fim e ao cabo, a história que Hobbes contou sobre as condições externas de uma política de Estados soberanos pode ser ainda mais fatídica do que a história que contou sobre o que se passa dentro de tais Estados. Esta não é uma história sobre um estado de guerra. É uma história de como supostamente temos que pensar nossas origens e limites como sujeitos modernos. A teoria política internacional não pode ignorar isso.

\section{Notas}

1. Estes são mais ou menos os termos nos quais tento me engajar com a articulação espaço-temporal da análise de política moderna em Walker (1993).

2. Como examinado minuciosamente, por exemplo, por Albert Hirshman (1977) e muitos outros.

3. Para uma maneira mais elaborada de tratar quais poderiam ser essas questões, ver R. B. J. Walker (2010). 
BULL, Hedley. The anarchical society. London: Macmillan, 1977.

HIRSHMAN, Albert. The passions and the interests. Princeton: Princeton University Press, 1977.

HOBBES, Thomas. Leviathan. Cambridge: Cambridge University Press, 1991.

WALKER, R. B. J. Inside/Outside: International Relations as political theory. Cambridge: Cambridge University Press, 1993.

. After the globe, before the world. London: Routledge, 2010.

WIGHT, Martin. Why is there no International Theory? In: BUTTERFIELD, H.; WIGHT, M. (Ed.). Diplomatic investigations. London: George, Allen and Unwin, 1966.

\section{Resumo}

\section{Por Que Ler Hobbes como um Teórico de Segurança Internacional?}

Thomas Hobbes tornou-se uma figura canônica para teorias de segurança internacional, ainda que seus escritos digam relativamente pouco acerca do que chamaríamos hoje de um sistema internacional. Este artigo sugere que Hobbes permanece importante para a análise de segurança internacional, assim como para a teoria política de modo mais geral, não por desenvolver qualquer teoria coerente de Relações Internacionais, mas sim porque sua consideração sobre a soberania de Estados particulares exige uma análise sobre as condições de possibilidade externas de tais Estados. Uma política após Hobbes precisa tratar dos efeitos constitutivos de sua filosofia da história particular. Assim, este artigo propõe uma leitura política de Hobbes, a qual enfatiza sua importância para o pensamento da política moderna e de 


\section{R. B. J. Walker}

suas condições de possibilidade; de suas origens e limites, que são também nossas origens e limites enquanto sujeitos modernos.

Palavras-chave: Hobbes - Política Moderna - Segurança Internacional - Filosofia da História

\section{Abstract}

\section{Why Read Hobbes as a Theorist of International Security?}

Thomas Hobbes has become a canonical figure for theories of international security even though his writings say relatively little about what we would now call an international system. This paper suggests that Hobbes remains important for the analysis of international security, as well as for political theory more generally, not because he advances any coherent theory of international relations but because his account of the sovereignty of particular states requires an account of the external conditions of possibility of such states. Politics after Hobbes needs to get to grips with the constitutive effects of his particular philosophy of history. Thus, this paper proposes a political reading of Hobbes that emphasizes his importance for thought about modern politics and its conditions of possibility; about its origins and limits that are also our origins and limits as modern subjects.

Keywords: Hobbes - Modern Politics - International Security Philosophy of History 